\title{
Seismic analysis of parallel structures coupled by lead extrusion dampers
}

\author{
C. C. Patel ${ }^{1}$
}

Received: 27 October 2016/Accepted: 29 April 2017/Published online: 12 May 2017

(c) The Author(s) 2017. This article is an open access publication

\begin{abstract}
In this paper, the response behaviors of two parallel structures coupled by Lead Extrusion Dampers (LED) under various earthquake ground motion excitations are investigated. The equation of motion for the two parallel, multi-degree-of-freedom (MDOF) structures connected by LEDs is formulated. To explore the viability of LED to control the responses, namely displacement, acceleration and shear force of parallel coupled structures, the numerical study is done in two parts: (1) two parallel MDOF structures connected with LEDs having same damper damping in all the dampers and (2) two parallel MDOF structures connected with LEDs having different damper damping. A parametric study is conducted to investigate the optimum damping of the dampers. Moreover, to limit the cost of the dampers, the study is conducted with only $50 \%$ of total dampers at optimal locations, instead of placing the dampers at all the floor level. Results show that LEDs connecting the parallel structures of different fundamental frequencies, the earthquake-induced responses of either structure can be effectively reduced. Further, it is not necessary to connect the two structures at all floors; however, lesser damper at appropriate locations can significantly reduce the earthquake response of the coupled system, thus reducing the cost of the dampers significantly.
\end{abstract}

Keywords Damping · Lead extrusion damper - Optimum placement $\cdot$ Parallel structures · Passive control - Seismic effect

C. C. Patel

ccstruct@gmail.com

1 Department of Civil Engineering, Marwadi Education Foundation Group of Institution, Rajkot 360003, India

\section{Introduction}

Various control devices and mechanisms had been developed for safety and reliability of engineering structures against natural loads like strong wind and earthquakes. The control mechanisms (can modify the dynamic response of structures in an alluring way), termed as protective system, for the new structures and the existing structures can be retrofitted viably for future seismic event. The energy consumptions of control systems for their operation classify them as passive system (does not require any external power), active system (requires large amount of external power), semi-active system (requires less amount of external power) and hybrid system (Spence and Nagarajaiah 2003). The papers by Kasai and co-author on current status of building passive control in Japan (Kasai et al. 2008a), on testing and analysis of full-scale 5-story steel frame with damper (Kasai et al. 2008b), and other past studies affirm that the passive control devices are effective for seismic response control of structures. In this way, passive control using energy-absorbing devices has gotten extensive consideration as of late.

Amongst the various passive control devices, LED is a powerful vitality energy dissipation device used for seismic protection of the structures. Various extrusion energy absorbers had been tested and it was found the devices behaved as plastic solids or coulomb dampers with nearly rectangular hysteresis loops and little rate dependence (Robinson and Greenbank 1976). The amount of energy absorbed is not limited by work hardening and fatigue of the lead, but the heat capacity of the device (i.e. melting point of lead) being the upper limit to the operating temperature, and the device is able to absorb energy during a large number of earthquakes. On being expelled, lead recrystallizes immediately and recoups its unique 
mechanical properties before next expulsion. LED absorbs vibration energy by plastic deformation of lead and in this way mechanical energy is converted to heat. Both groups of LED (the constricted tube type and the bulged shaft type) use the similar fundamental concept of retaining the resistive force by plastically expelling the lead through an orifice created by the annular restriction. The fundamentally concentrate on simplicity of fabrication and the capacity to achieve predictable and repeatable performance, and relative benefits of each type LED are archived (Cousins and Porritt 1993). A high force to volume proportion likewise empowers such expulsion dampers to be straightforwardly fitted into the segments of steel frame buildings, giving hysteretic energy absorption in the beamcolumn connection without yielding of the principle basic steel components of the frame (Rodgers et al. 2008). Muthmani and co-author had performed the experimental investigations of the lead extrusion damper for energy absorption (Muthmani et al. 2002). The control system and the structure do not act as independent dynamic systems but instead interact with each other. What is more, interaction effects also occur between the excitation and structure (i.e. soil-structure interaction).

Among various control techniques, interconnecting parallel structures when possible, is one of the effective techniques for seismic protection of the structures. The idea is to exert control forces upon one another of dynamically dissimilar connected structures to reduce the overall responses of the coupled system. Be that as it may, it alters the dynamic characteristics of the unconnected structures, and in-case of asymmetric geometry, it increases undesirable torsional response and base shear of stiffer structure. Connecting parallel structures likewise supportive to help beat the issue of the pounding, more hazardous condition than earthquake, observed during past earthquake events, for example 1985 Mexico City (Betro 1987), 1989 Loma Prieta earthquake and many others. The available free space between parallel structures can be adequately used; in this way, extra space is not required for installation of damping devices. To avoid pounding damages during earthquakes, the idea of linking parallel fixed-base buildings had been introduced and verified analytically and experimentally by a number of researchers (Westermo 1989; Filiatrault and Folz 1992; Weidlinger 1996). Seismic response of base-isolated adjacent structures connected by viscous damper had been analyzed (Matsagar and Jangid 2003). The dynamic behavior of two adjacent single-degree-of freedom (SDOF) structures connected with a friction damper under harmonic ground acceleration had been investigated (Bhaskararao and Jangid 2006). A series of shaking table tests were carried out on one 3-story and one 12 -story building models in fully separated, rigidly connected, and friction damper-linked configurations to explore the possibility of passive friction dampers to connect the podium structure to the main buildings ( $\mathrm{Ng}$ and $\mathrm{Xu}$ 2006). The close-form expressions were derived for solving the vibration control problem of connecting two adjacent structures. The dynamic behavior of two adjacent SDOF structures connected with a viscous damper under harmonic excitation as well as stationary white-noise random process had been studied and close-form expression for optimum damping of damper for undamped structures had been derived (Bhaskararao and Jangid 2007). The effects of the building configuration and damper location on the overall system performance, considering passive and active coupled building control for flexible adjacent buildings modeled as cantilevered beams using the Galerkin method, had been investigated (Christenson et al. 2006). The seismic response of adjacent steel structures connected by passive devices (linked by linear viscous dampers and linear springs) are analyzed; the influence of structural properties and properties of the excitation on the responses have been investigated, and the results show that connecting adjacent structure by viscous damper is effective for response control of the structures (Roh et al. 2011). The effectiveness of passive damper for response control of dynamically well-separated adjacent coupled structures has been confirmed by above studies. However, the response behaviors of parallel MDOF structures connected by LEDs, subjected to real earthquake ground motion excitations, have not been explored. The present study is intended to investigate the performance of LED for response control of two parallel MDOF structures under real earthquake excitations. The specific objectives of the study are summarized as to (1) investigate the effects of variation in damping coefficient of LED on controlled structural responses, (2) identify the optimum damping of LED, (3) investigate the hysteretic energy dissipation behavior of the LED and (4) determine the optimal location to minimize the cost of the dampers.

\section{Structural model}

The two MDOF structures, with their symmetric planes in alignment, are considered as appeared in Fig. 1. The ground motion is assumed to occur in one direction in the symmetric planes of the structure to simplify the problem as a two-dimensional problem. Considering the enhanced energy-absorbing capacity of the structures because of the connected dampers, the structures are assumed to remain in linear-elastic. The height of each structure can be different, but the floors of each structure are assumed at the same level. Each structure is considered as flexible, shear type of structure with lateral degree-of-freedom at the floor level. The total plan dimensions in the direction of excitation are 


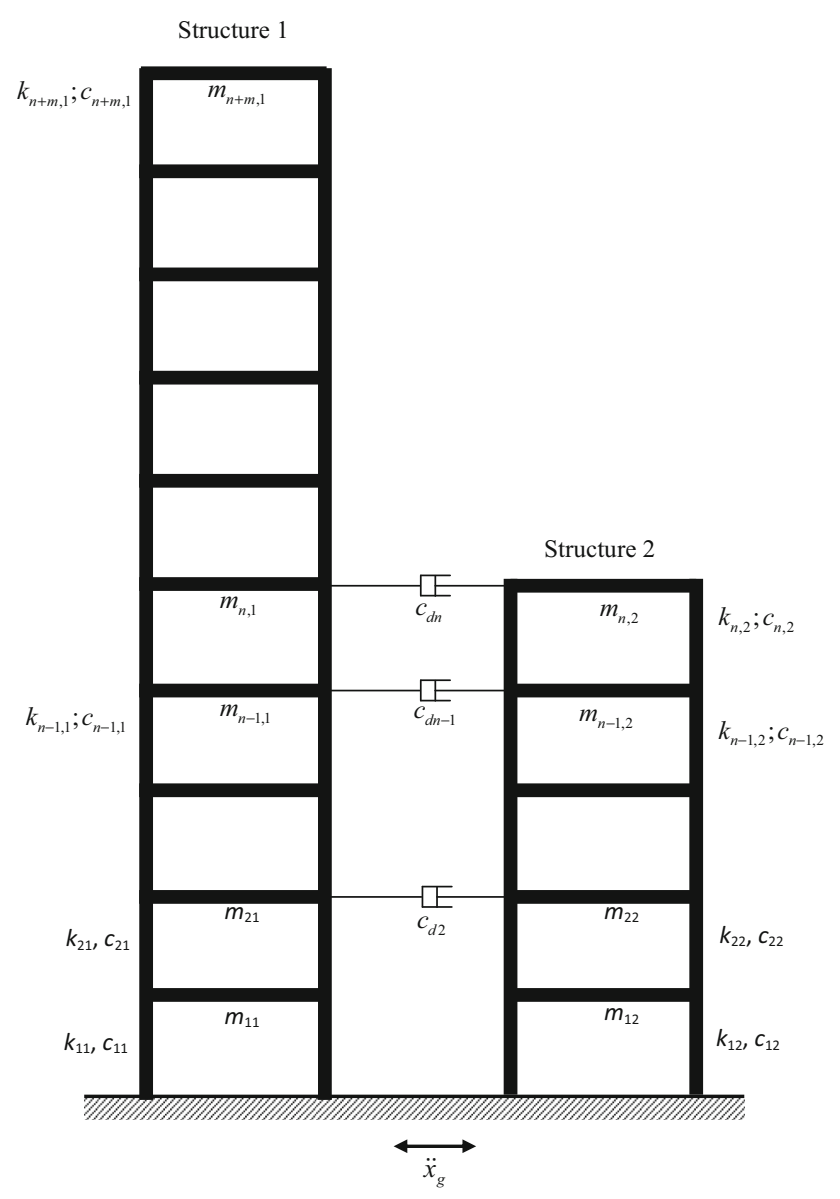

Fig. 1 Structural model of two MDOF parallel structures connected by LED

not large, so any effect due to spatial variations of the ground motion are neglected. The soil-structure effect is also neglected, limits the applicability of the results to structures on stiff, firm ground and, less restrictively, to structures with foundations that are not massive (e.g. footing foundations).

Let Structure 1 have $m+n$ and Structure 2 have $n$ stories as show in Fig. 1. The mass, damping coefficient and lateral stiffness value for the $i$ th story are $m_{i 1}, c_{i 1}$ and $k_{i 1}$ for Structure 1 and $m_{i 2}, c_{i 2}$ and $k_{i 2}$ for Structure 2, respectively. The coupled system will then have a total $2 n+m$ number of degree-of-freedom. The governing equation of motion for the LED connected system is expressed in the matrix form as

$M \ddot{u}+C \dot{u}+K u+\Lambda F=-M I \ddot{u}_{\mathrm{g}}$,

where $M, C$ and $K$ are the mass, damping and stiffness matrices of the connected structure system; $F$ a vector consisting of the control force in the LEDs; $\Lambda$ is a matrix of zeros and $1 \mathrm{~s}$, where 1 will indicate where the damper force is being applied; $I$ is a vector with all its element equal to unity; $u$ is relative-displacement vector with respect to the ground, and the first $n$ position is Structure 2's displacement and last $m+n$ position is Structure 1's displacement; $\dot{u}$ and $\ddot{u}$ represent the first and second time derivatives of $u$, respectively; and $\ddot{u}_{g}$ is the ground acceleration at the foundations of the structures. Each each matrix is given in detail as

$$
\begin{gathered}
M=\left[\begin{array}{cc}
m_{(n, n)} & 0_{(n, n+m)} \\
0_{(n+m, n)} & m_{(n+m, n+m)}
\end{array}\right] ; \\
C=\left[\begin{array}{cc}
c_{(n, n)} & 0_{(n, n+m)} \\
0_{(n+m, n)} & c_{(n+m, n+m)}
\end{array}\right] ; \\
K=\left[\begin{array}{cc}
k_{(n, n)} & 0_{(n, n+m)} \\
0_{(n+m, n)} & k_{(n+m, n+m)}
\end{array}\right],
\end{gathered}
$$

$k_{(n+m, n+m)}=\left[\begin{array}{cccc}k_{11}+k_{21} & -k_{21} & & \\ -k_{21} & k_{21}+k_{31} & -k_{31} & \\ & \cdots & \cdots & \\ & & & k_{n+m, 1}\end{array}\right]$;

$k_{(n, n)}=\left[\begin{array}{cccc}k_{12}+k_{22} & -k_{22} & & \\ -k_{22} & k_{22}+k_{32} & & \\ & \ldots & \ldots & \\ & & & k_{n 2}\end{array}\right]$,

$F^{T}=\left\{\begin{array}{lll}-f_{d(n, 1)} & 0_{(m, 1)} & f_{d(n, 1)}\end{array}\right\}$,

$f_{d}^{T}=\left\{f_{d 1}, f_{d 2}, \ldots, f_{d i}, \ldots, f_{d n-1}, f_{d n}\right\}$,

$u^{T}=\left\{u_{12}, u_{22}, u_{32}, \ldots, u_{n-1,2}, u_{n, 2}, u_{11}, u_{21}, u_{31}, \ldots\right.$,

$$
\left.u_{n-1,1}, u_{n 1}\right\} \text {; }
$$

' 0 ' is the null matrix, where $f_{d i}$ is the force in the $i$ th damper connecting the floors, $u_{i 1}$ and $u_{i 2}$ of the Structures 1 and 2, respectively. The relationship between force and velocity of the LED is highly nonlinear; thus force in the $\operatorname{LED} f_{d i}$ is assumed to be non-linear, proportional to the relative velocity of the damper ends, and is approximated 
Fig. 2 Damper forcedisplacement and force-velocity relationship for the damper
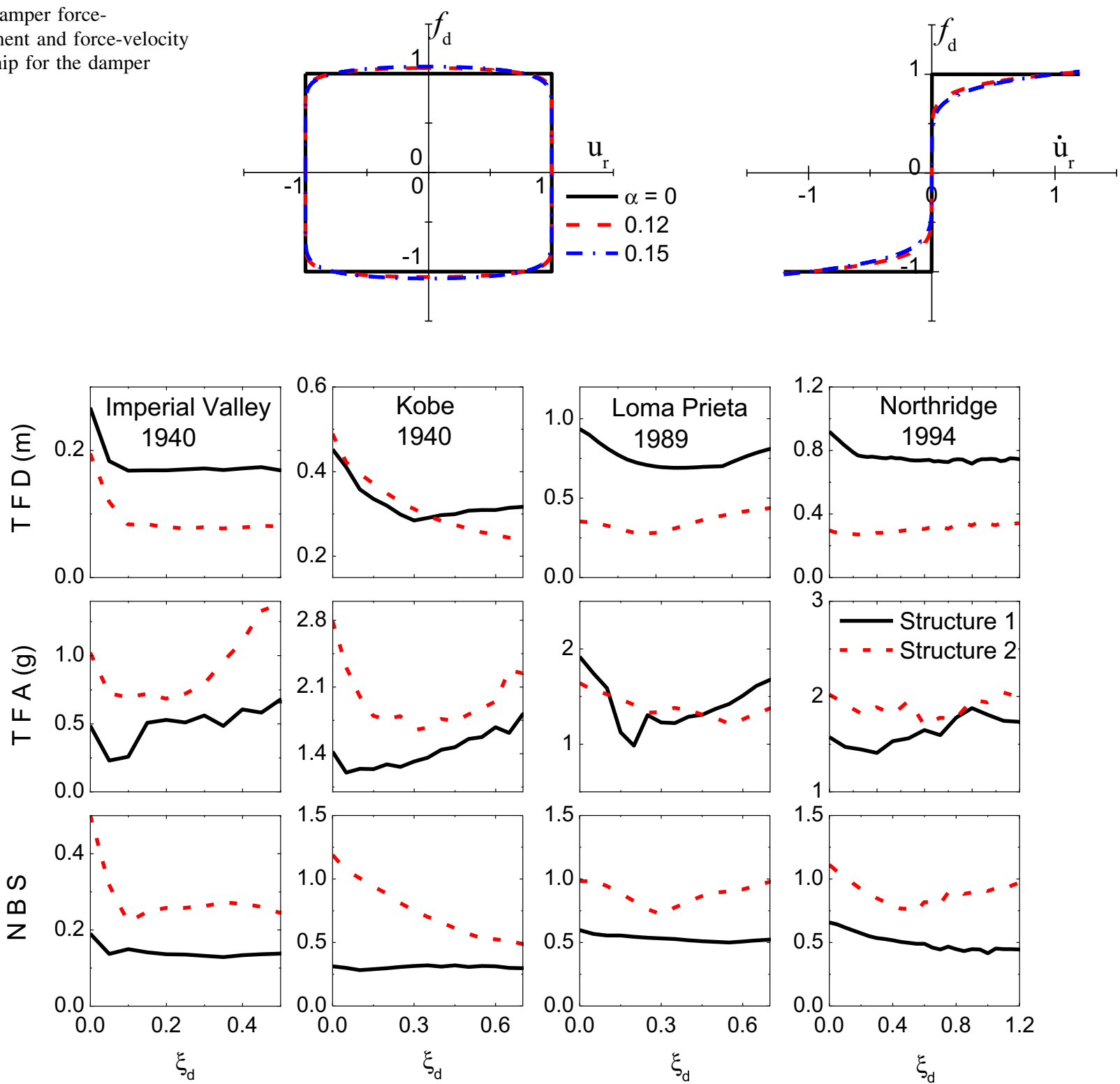

Fig. 3 Variation of peak responses of MDOF structures against normalized damping coefficient of LED having same damping

as Robinson and Greenbank (1976), Cousins and Porritt (1993) and Rodgers et al. (2008):

$f_{d i}=c_{d i}\left|\dot{u}_{r i}\right|^{\alpha} \operatorname{sgn}\left(\dot{u}_{r i}\right)$,

where $c_{d i}$ is damping coefficient of $i$ th damper, $\dot{u}_{r i}=$ $\dot{u}_{i 1}-\dot{u}_{i 2}$ is relative velocity of the $i$ th damper ends and sgn denotes the signum function. The nonlinear damper damping can be evaluated by various methods like energy balance approach, equating the energy dissipated in a vibration cycle of the actual non-linear and equivalent viscous system; equivalent power consumption approach, equating the average power consumption of nonlinear damper and equivalent damper over one cycle of oscillation (Pekcan et al. 1999). The damping coefficient of damper $c_{d i}$ is expressed in the normalized form as

$\xi_{d i}=\frac{c_{d i}}{2 m_{11} \omega_{11}}$

where $m_{11}$ and $\omega_{11}$ are the mass of first floor and the first natural frequency of Structure 1, respectively; and $c_{d i}$ is the damping coefficient of $i$ th damper. For bulged shaft LED, the value of velocity exponent $\alpha$ is in the range of $0.11-$ 0.15 (Cousins and Porritt 1993). For present study the $\alpha$ value is considered as 0.12 . The force-displacement and force-velocity relationship for LED, considering $\alpha=0.12$ and 0.15 , is shown in Fig. 2. The elastic-plastic behavior by these LED provides an almost ideal square hysteresis 
Structure 1

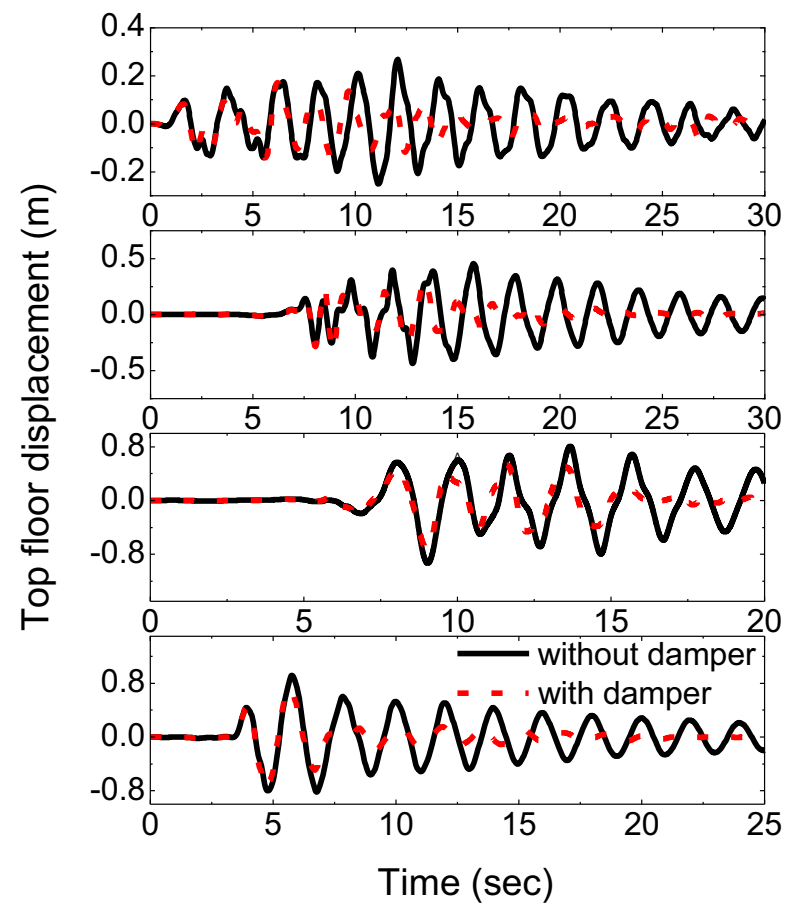

Structure 2
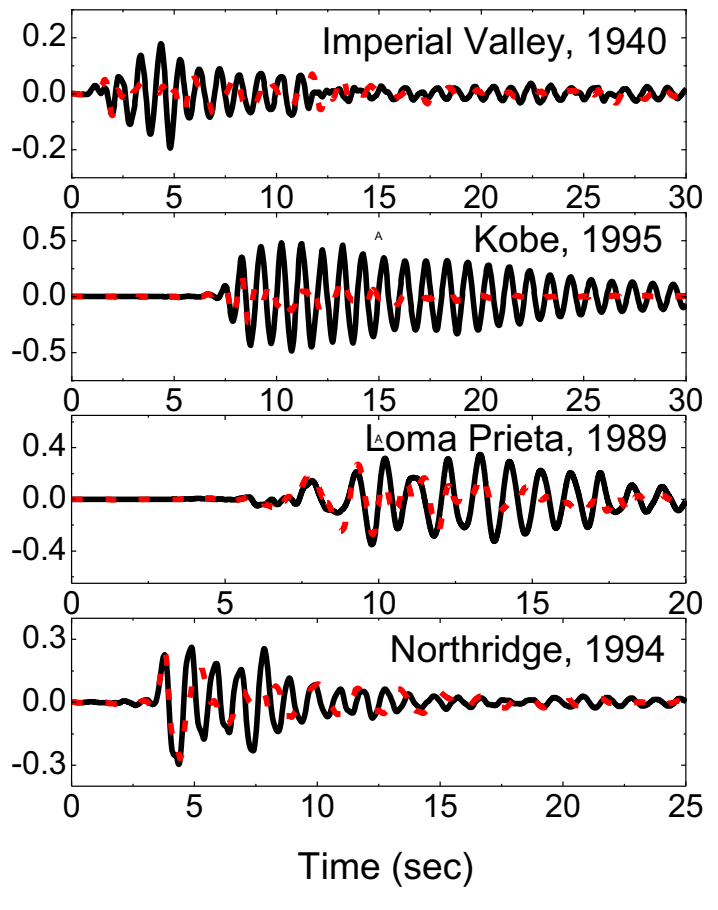

Fig. 4 Time histories of the top floor displacement of the two MODF structures

Structure 1

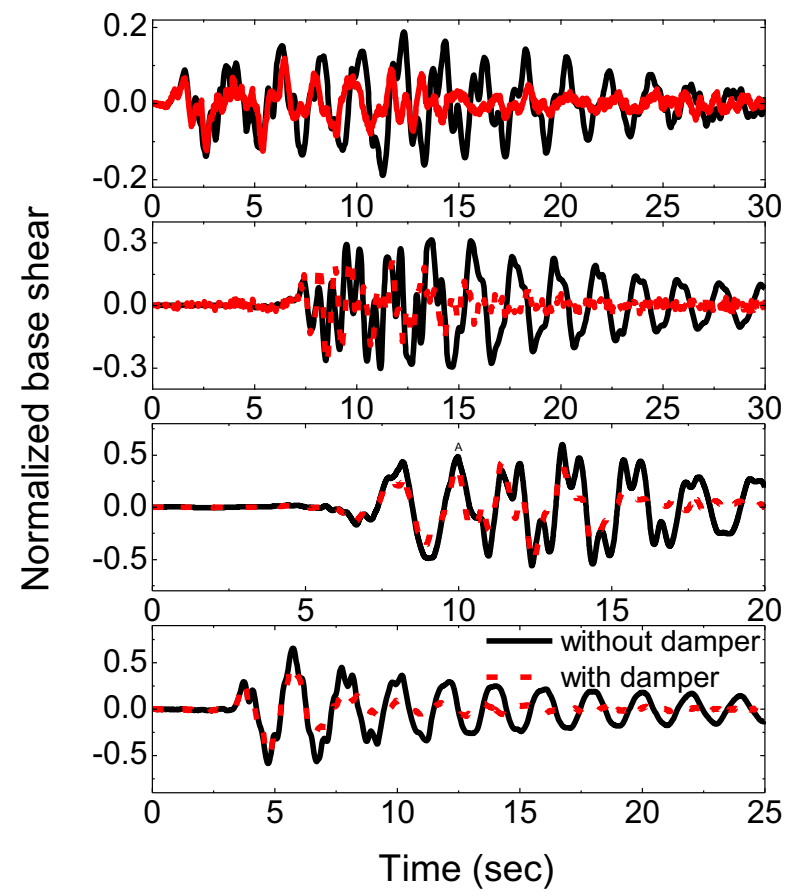

Structure 2
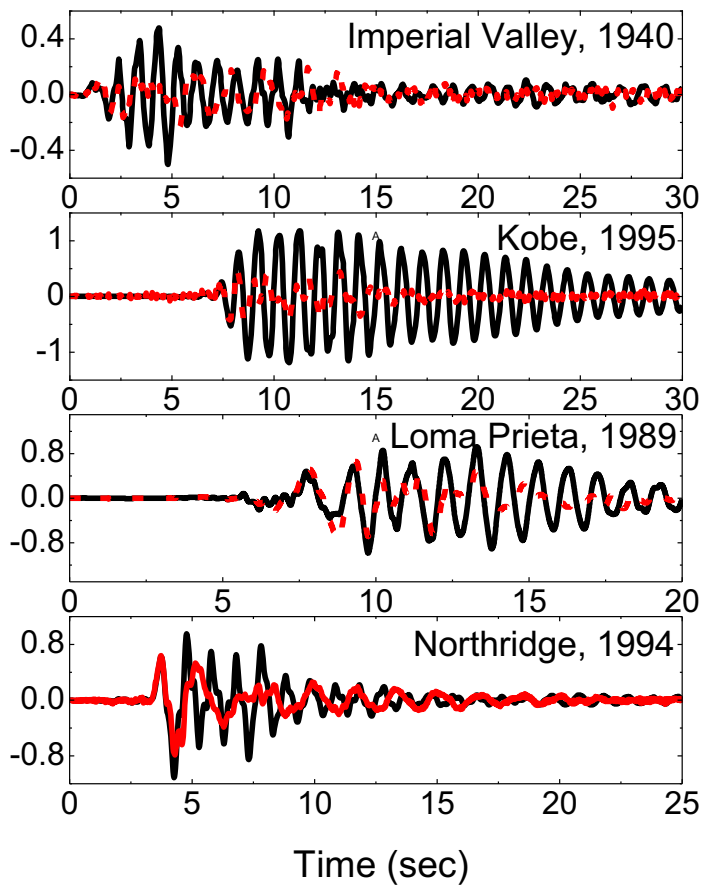

Fig. 5 Time histories of the base shears of the two MDOF structures

loop. It encloses the maximum possible area within the force-displacement plane, providing the maximum energy dissipation achievable per cycle. As the force-velocity relationship of the LED is highly nonlinear, LED connected structure system has nonlinear properties, even supposing that the structures behave linearly; thus, 
Fig. 6 Control force-

displacement diagram for 12 th

floor LED with the parallel

structures connected at all floors

under different earthquakes
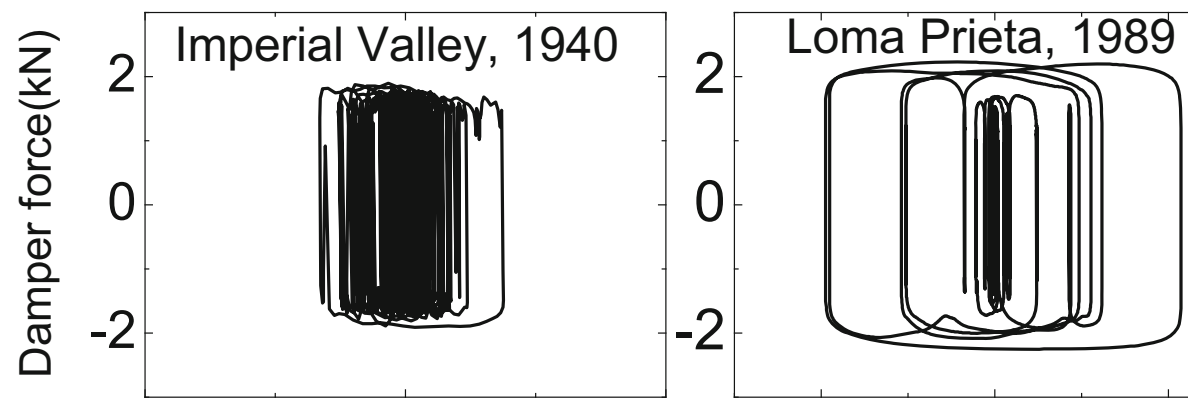

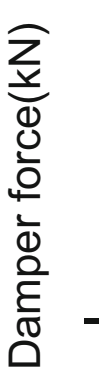

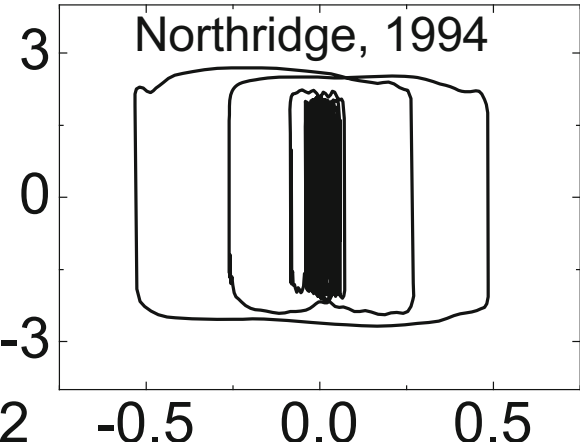

Damper dispalcement(m)
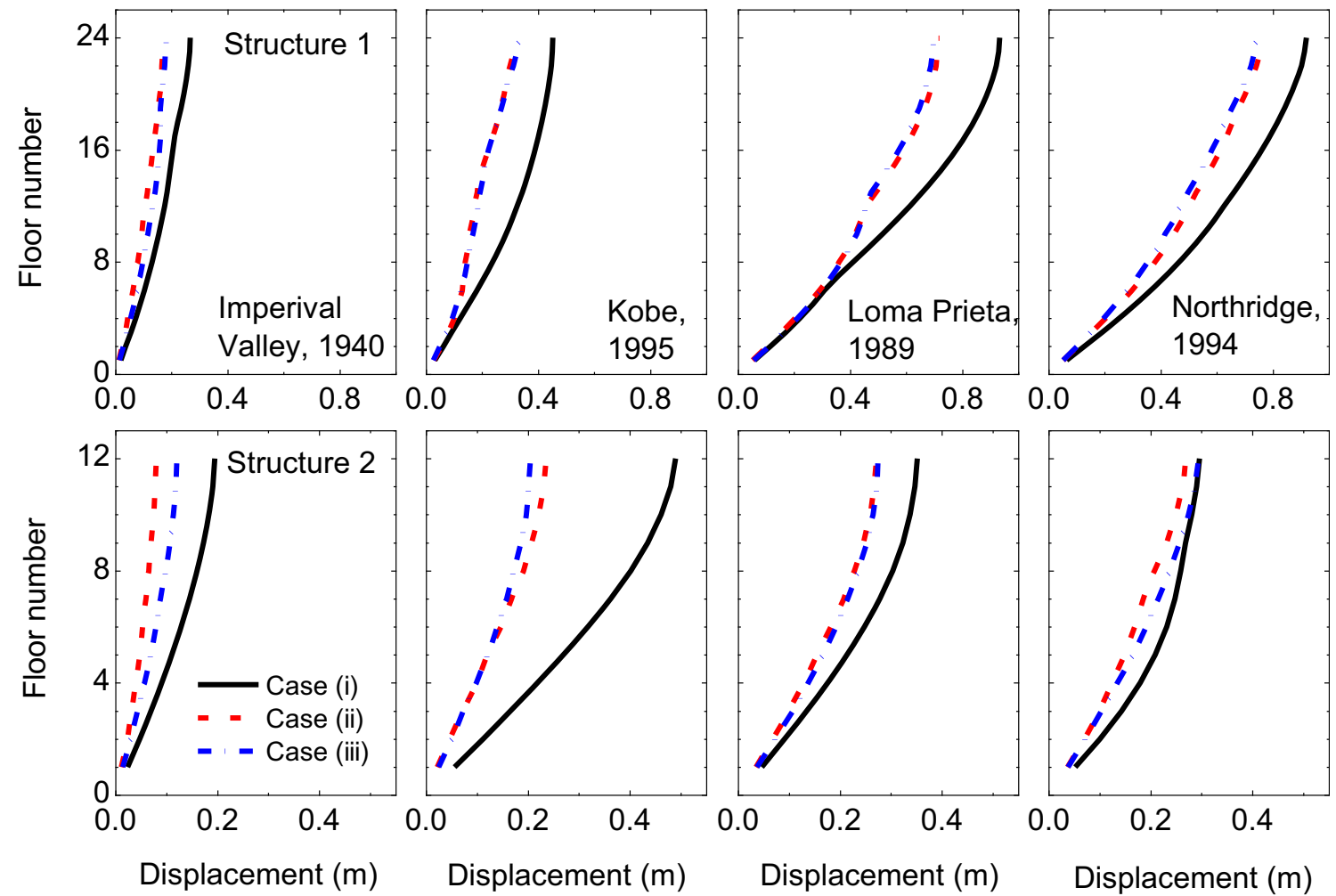

Fig. 7 Variation of the peak displacements along the floors 

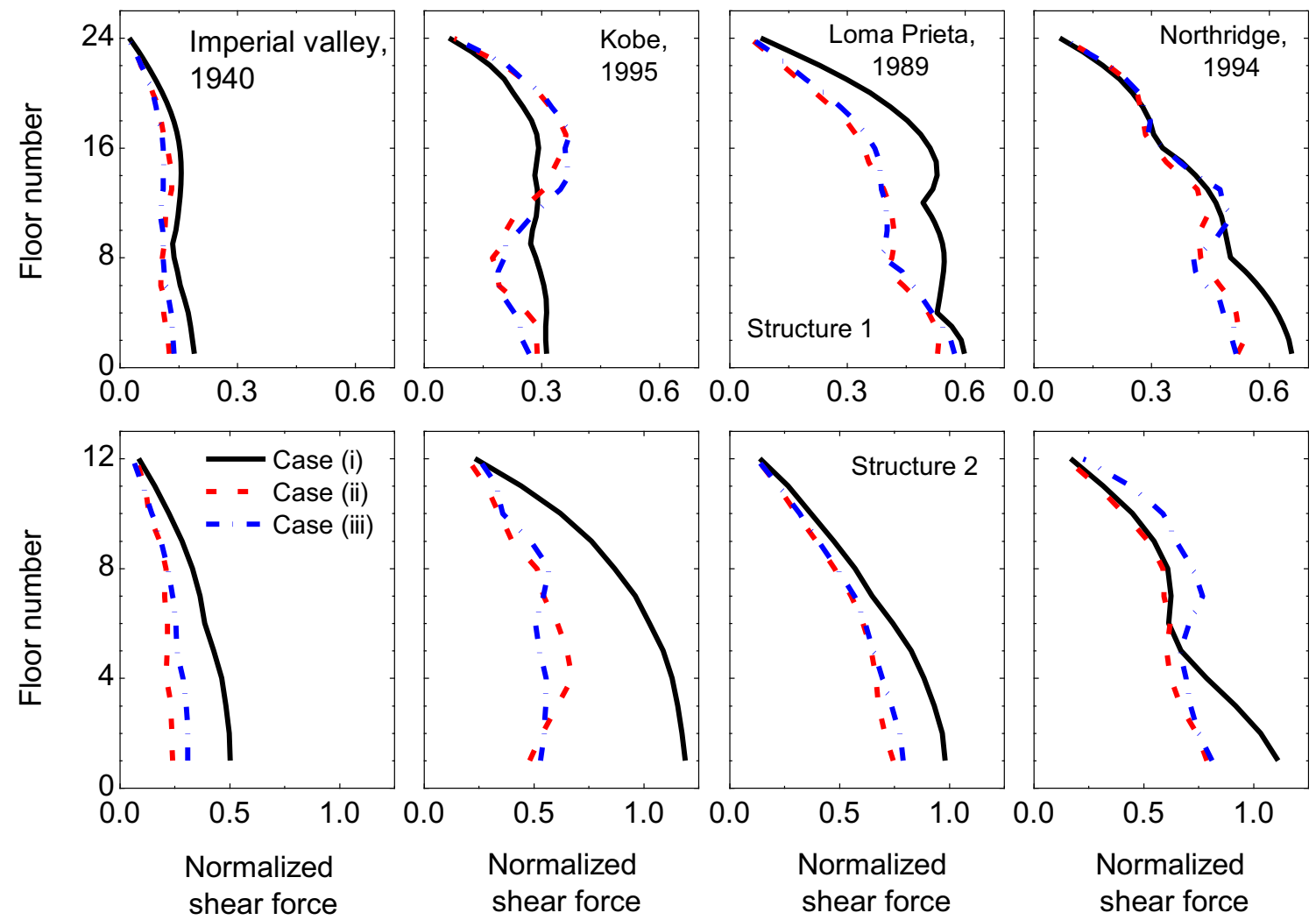

Fig. 8 Variation of the peak shear forces along the floors

governing equations of motion are solved in the incremental form using Newmark's step-by-step method considering average acceleration over small time interval $\Delta t$.

\section{Numerical study}

An exhaustive study is conducted to recognize optimum damping coefficient of LEDs for MDOF parallel structures under different earthquake excitations. The earthquake ground motions considered to examine the seismic behavior of the coupled structures are: NOOE component of Imperial Valley, 1940 with peak ground acceleration (PGA) $0.32 \mathrm{~g}$ (g is the acceleration due to gravity), N90E component of Kobe, 1995 with PGA 0.63 g, N90E component of North-ridge, 1994 with PGA $0.84 \mathrm{~g}$, and NO0E component of Loma Prieta, 1989 with PGA 0.57 g. The study is divided into two parts: (1) adjacent MDOF structures connected by LEDs having same damping coefficient in all dampers and (2) adjacent MDOF structures connected by LEDs having different damping coefficient in all dampers. The response quantities of interest are peak top floor relative displacement, peak top floor absolute accelerations and peak base shears. The base shear value is normalized with the weight of the structure to get the normalized shear force.
Two MDOF Structures connected by LEDs having same damping coefficient in all the dampers

The two 24- and 12-story adjacent structures with uniform floor mass and inter-story stiffness for both the structures are considered. The masses of the two structures are assumed to be same and the damping ratio in each structure is taken as $2 \%$. The later stiffness of each floor of the structures is chosen such that to yield fundamental time periods of 2.0 and $1.0 \mathrm{~s}$ for Structure 1 and 2, respectively. For the uncontrolled system, the first three natural frequencies corresponding to first three modes of the Structure 1 are $3.1415,9.4117,15.6432 \mathrm{rad} / \mathrm{s}$, and that of the Structure 2 are $6.2831,18.7503,30.9218 \mathrm{rad} / \mathrm{s}$, respectively. These frequencies show that the modes of the structures are well separated. Thus, Structure 1 may be considered as softer structure and Structure 2 as stiffer structure.

The variation of the top floor relative displacements, top floor absolute accelerations and normalized base shears of the two structures are plotted with normalized damping coefficient of damper and are shown in Fig. 3, for all the four considered earthquakes. The figure shows that the responses of both the structures are reduced up to a certain increase in the damping coefficient of damper and with further increase in the damper damping they again 
Fig. 9 Control forcedisplacement diagram for 12th floor LED when the parallel structures connected at top six floors under different earthquakes

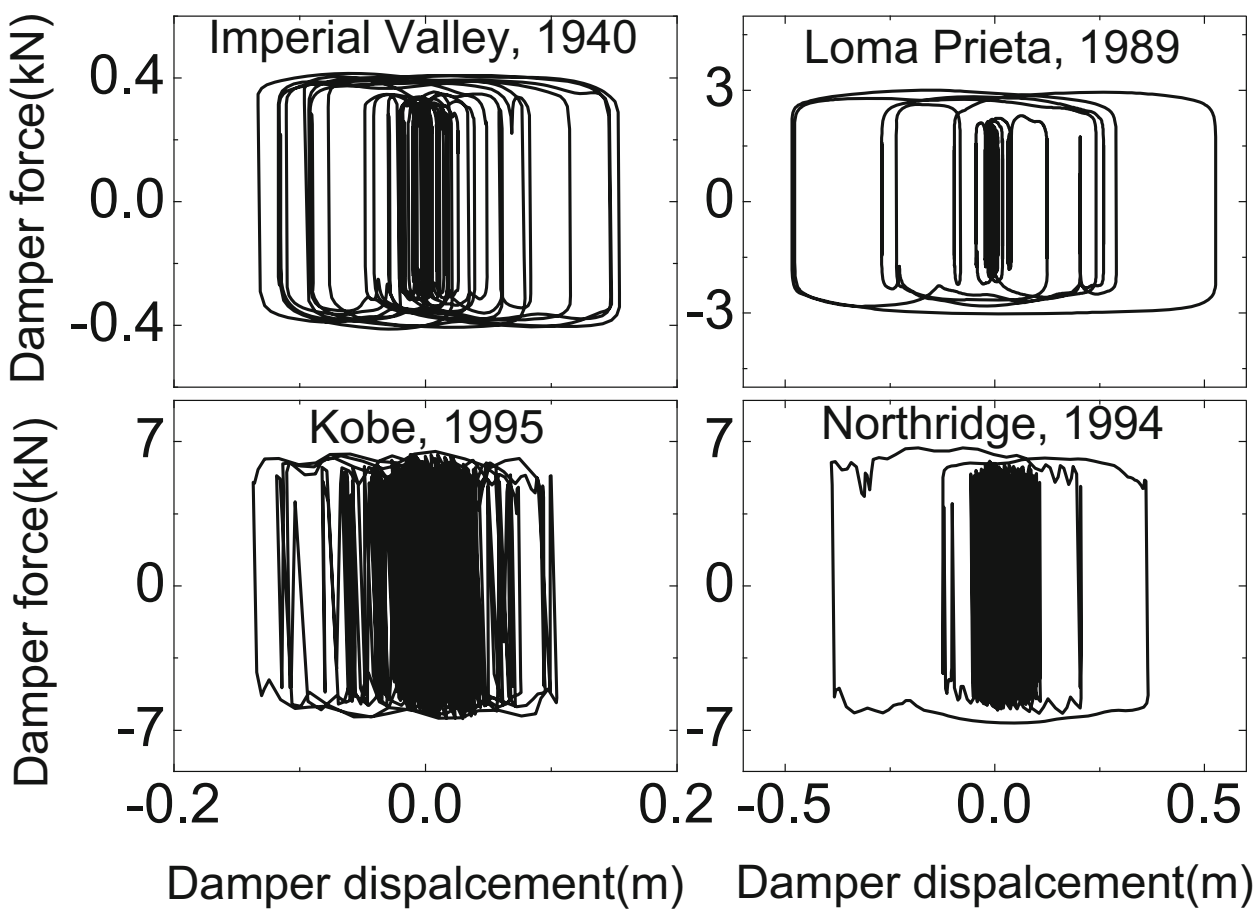

increase. The optimum damping coefficient of damper exists to attain the minimum response in both the structures. As the optimum damper damping is not exactly the same for both the structures, the optimum value is considered which gives minimum sum of the responses of the two structures. For optimum damper damping value, the emphasis is given on the displacements and base shears of the two structures and at the same time care is taken that acceleration of the structures, as far as possible, are not increased. It is also observed that optimum damper damping value is different for different earthquakes. Thus, the characteristics of the earthquake motion like PGA, frequency content, large magnitude, near field, etc., influence the optimum damper damping. For the damping coefficient of damper value reduced to zero, the two structures return to unconnected condition. On the other hand, at very high damper damping, the two structures behave as though they are rigidly connected. The relative displacements and the relative velocities of the connected floors reaches nearer to zero, results damper loses its effectiveness.

The time history for the top floor displacement and base shear responses of the two structures connected by LEDs with optimum damper damping at all floors is shown in Figs. 4 and 5, respectively. These figures indicate the LED effectiveness in controlling the earthquake response of both structures. The force-displacement relationship for 12 th floor LED, under different earthquakes, is shown in Fig. 6. It shows the LED effectiveness for energy dissipation during seismic response of the connected structures. It is also observed that energy dissipation behavior of LED is different during different earthquake ground motions. The LED is more effective for energy dissipation during Kobe, 1995 and Loma Prieta, 1989 earthquake ground motions than Imperial Valley, 1940 and Northridge, 1994 earthquake ground motions. Thus, the characteristics of the ground motion influence the performance of the LED.

The responses of adjacent structures are investigated by considering only $50 \%$ of total (6 dampers) with optimum damper damping at selected floor locations. To arrive at the optimal placement of the dampers, many trials are carried out, like providing dampers at alternate floors, top six floors, bottom six floors, etc. The variations of the displacements and shear forces in all the floors for three different cases, namely when case (1) unconnected, case (2) connected at all the floors, and case (3) connected at top six floors are shown in Figs. 7 and 8, respectively. It is observed from the figure that when the dampers are attached to top six floors, the displacement and shear forces in all the stories are reduced as much as when they are connected at all the floors. However, from Fig. 8, it is observed that for Kobe, 1995 earthquake wherein for Structure 1 the shear force is increased above the 12 th floor. Structure 1 suffers high-story shear above the height of the shorter structures, because the sway of the taller structure is restricted by the shorter structure. It leads to conclude that the structural behavior and its improvement are also influenced by the characteristics of the earthquake ground motion. Therefore, it is recommended to carry out a specific and thorough study for the problem under 


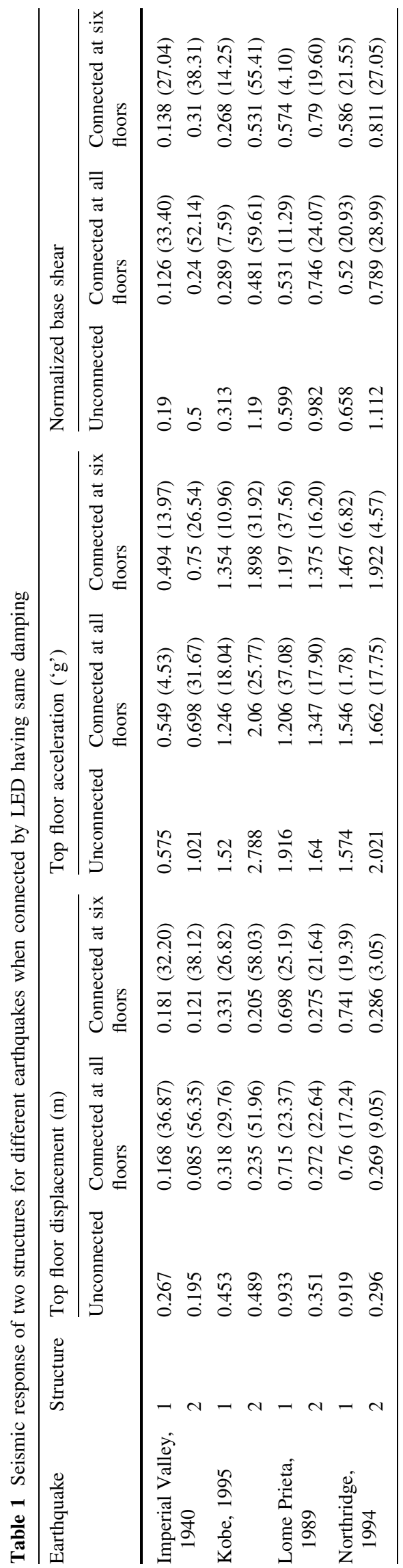

consideration before deciding the final control strategy. The force-displacement relationship for 12th floor LED, when adjacent structures are connected at top six floors, under different earthquakes is shown in Fig. 9. It is observed that the energy dissipation capacity of LED increases and is different under different earthquake ground excitations.

The peak top floor displacement, peak top floor accelerations and normalized base shear quantities and its reductions of the two structures for unconnected, connected with LED at all floors, and connected with only six LEDs at top floors are shown in Table 1. From the table it is observed that the reduction in the responses for the two different damper arrangement is almost similar and decrease in the reduction of the responses of the two structures with only six dampers (50\% dampers) is not more than $10 \%$ of that obtained for the two structures connected at all the floors. Thus, lesser dampers at appropriate locations of connected structure system can reduce the earthquake responses significantly and reduces the cost of the dampers also.

\section{Two MDOF structures connected with LED having different damping in the dampers}

As the force in LED depends on the relative velocity of the connected floors, whereas, in the previous section, the damping coefficient of LED is taken to be the same irrespective of its location along the height of the structures. The maximum damper end velocity will be high in the top-most damper, requiring a higher damping coefficient and is reducing when going towards the bottommost damper, requiring the lowest damping coefficient. Hence, here the investigation is carried out, choosing different damping coefficient in different damper. Thus, the damping coefficient in LED is varied according to the average variation of maximum relative velocities when structures are unconnected and the corresponding calculations to arrive at the variation of damping of LEDs are shown in Table 2.

For optimum damping coefficient of LED with different damper damping along the floors, the variation of the top floor relative displacements, top floor absolute accelerations and base shears of the two structures against normalized damper damping, varying along the floors, is shown in Fig. 10 for all the four earthquakes considered. It is almost similar observation to that observed in "Two MDOF Structures connected by LEDs having same damping coefficient in all the dampers". The optimum normalized damper damping will be in the top most damper (i.e. connecting 12th floors) and the normalized optimum damper damping in the other dampers is varied in the average variation shown in Table 2. 
Table 2 Percentage variation of maximum relative velocities between adjacent floors with respect to the top one

\begin{tabular}{lllllr}
\hline Floor No & Imperial Valley 1940 & Kobe 1995 & Loma Prieta 1989 & Northridge 1994 & Average \\
\hline 12 & 100 & 100 & 100 & 100 & 100.00 \\
11 & 95.52 & 97.15 & 93.85 & 93.77 & 95.07 \\
10 & 90.6 & 93.16 & 87.28 & 88.29 & 89.83 \\
9 & 85.16 & 88.01 & 81.15 & 83.74 & 84.52 \\
8 & 79.09 & 81.93 & 74.54 & 78.61 & 78.54 \\
7 & 72.26 & 74.81 & 68.26 & 72.59 & 71.98 \\
6 & 64.57 & 66.54 & 61.47 & 65.45 & 64.51 \\
5 & 55.98 & 57.23 & 53.43 & 57.09 & 55.93 \\
4 & 46.47 & 47.11 & 44.24 & 47.52 & 46.34 \\
3 & 36.01 & 36.11 & 34.06 & 36.84 & 35.76 \\
2 & 24.64 & 24.43 & 23.11 & 25.2 & 24.35 \\
1 & 12.53 & 12.32 & 11.68 & 12.82 & 12.34 \\
\hline
\end{tabular}
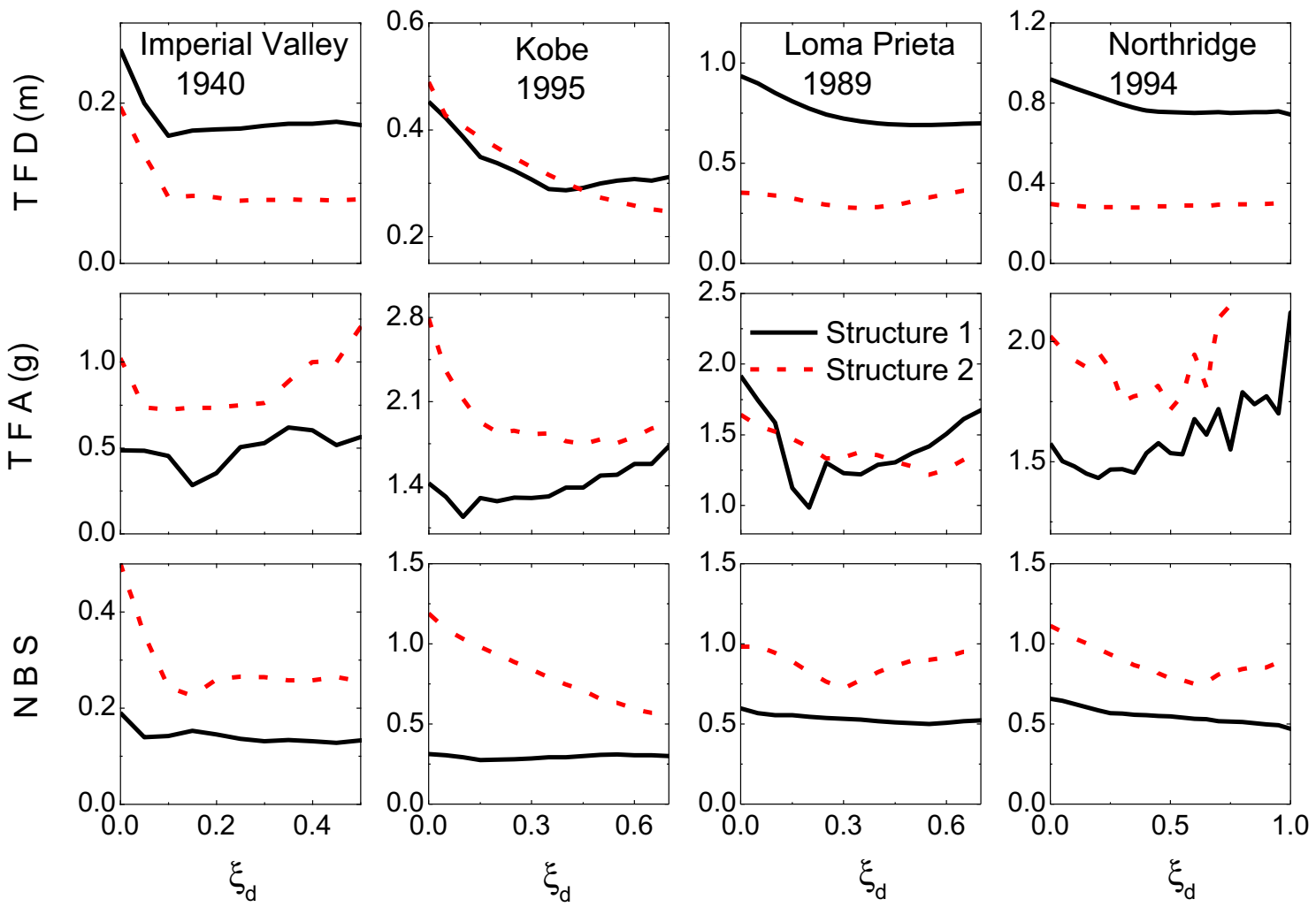

Fig. 10 Variation of peak responses of MDOF structures against normalized damping coefficient of LED having different damping

The variation of displacement and shear force responses of the two structures along the floors when connected at all the floors with LED having (1) same damper damping in all the dampers and (2) different damping in the LED along the height, is shown in Figs. 11 and 12, respectively. This clearly indicates that the same damper damping is not required in all the dampers and can be going on reducing from the top-most damper to the bottom-most damper in the same variation as the maximum relative velocity in the connecting floors varies. Thus, the cost of the dampers is also reduced to a great extent.

For optimum placement of the LED in this case also, the same procedure followed in the "Two MDOF Structures connected by LEDs having same damping coefficient in all the dampers" is followed and here also it is found that when LEDs are placed at 7-12 floors, the maximum reductions in the responses are achieved.

The reductions in the peak top floor displacements, peak top floor accelerations and normalized base shears of the 

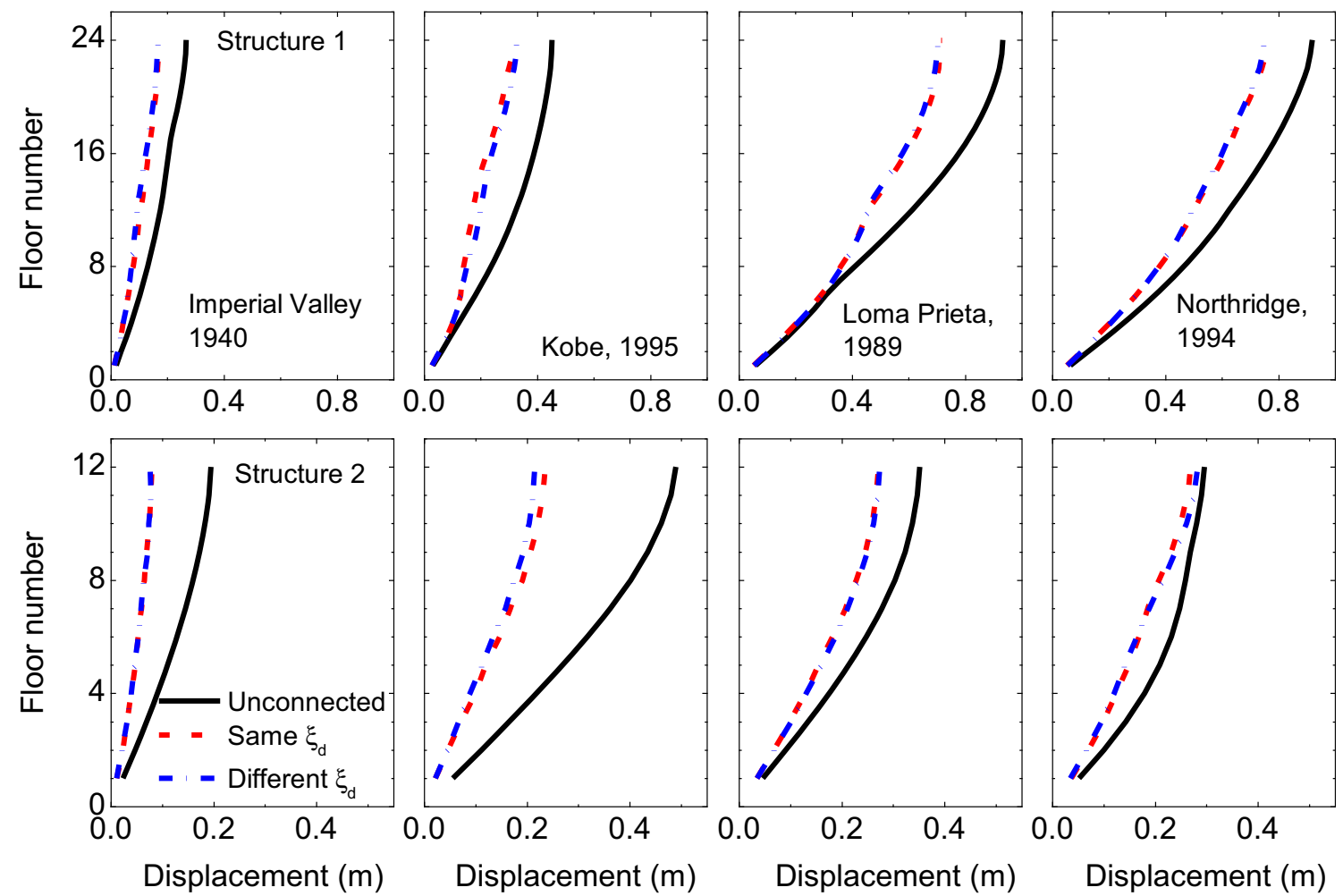

Fig. 11 Comparison of floor displacements for constant and different damping in the LEDs
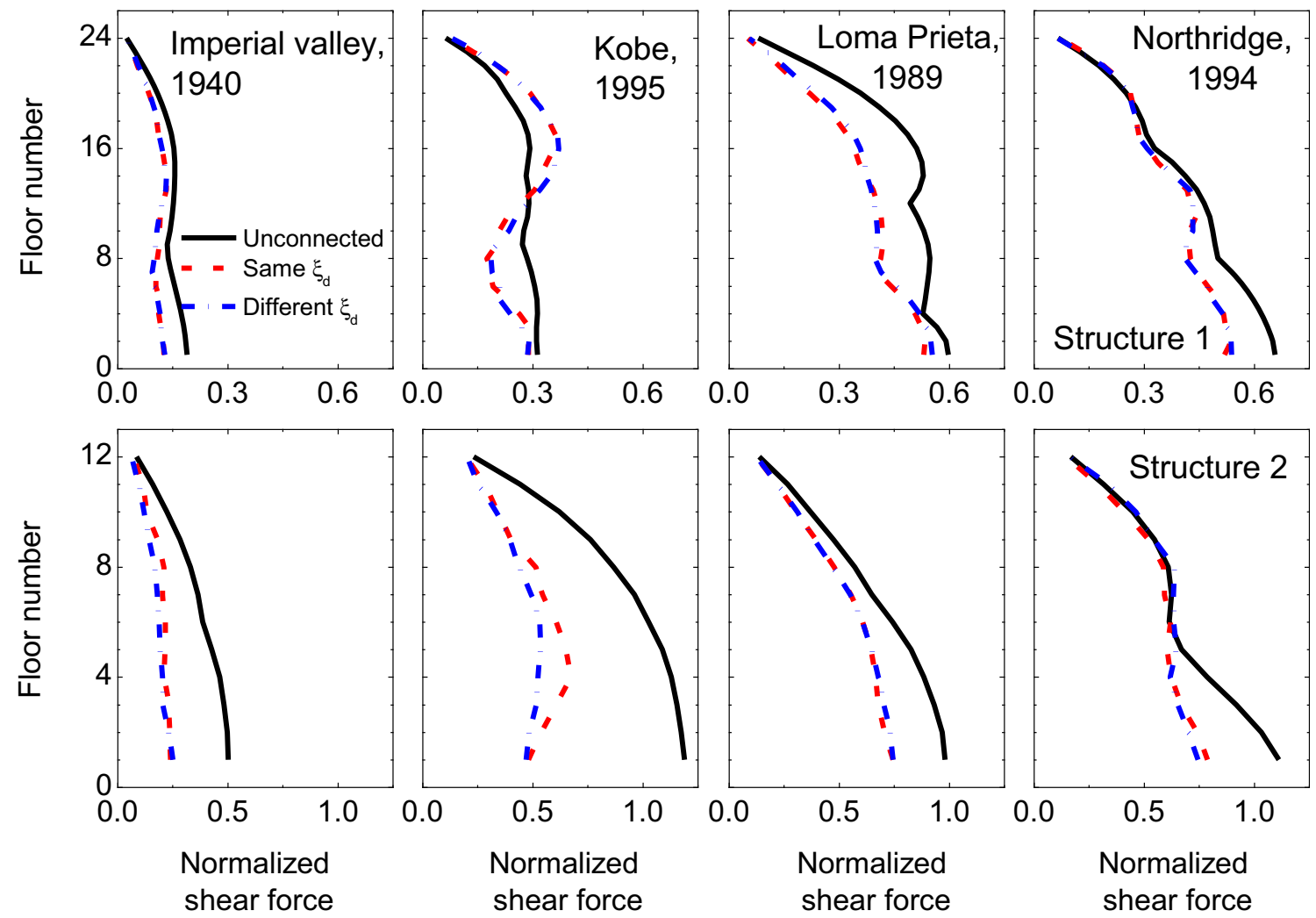

Fig. 12 Comparison of floor shear forces for constant and different damping in the LEDs 


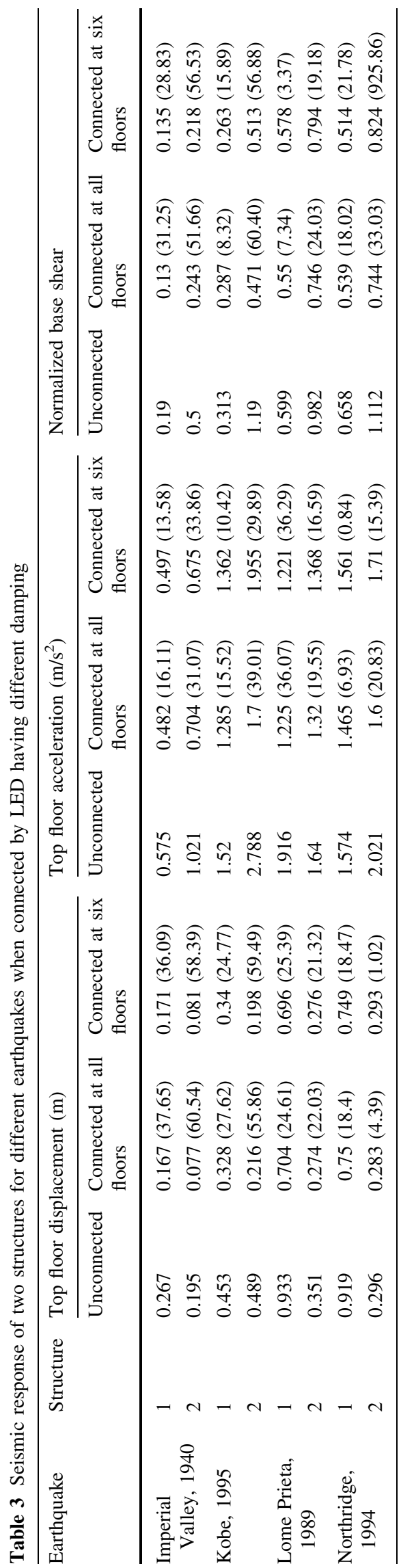

two structures for without dampers, connected with LED at all floors, and connected with only six LEDs at optimal locations are shown in Table 3. Here also it is observed that there is similar way of reduction in the responses for the two damper arrangements, and the decrease in the reduction of the responses of the two structures with only $50 \%$ dampers is not more than $10 \%$ of that obtained for the structures with dampers connected at all the floors. However, the various response quantity reductions under considered four earthquakes are different for different damper arrangements. The force-displacement for 12th floor LED, under different earthquake excitations, considering connected by different damper damping at all the floors and connected at top six floors by different damper damping, is shown in Figs. 13 and 14, respectively. It is observed from the figures that energy dissipation performance of the damper is different for different damper arrangement, even for same earthquake ground motion, leads to conclude that characteristic of earthquake ground motion as well as damper arrangement influences the structural behavior and its improvement. Therefore, it is necessary and recommended to carry out a thorough and specific study for the problem under consideration before being implemented in practice.

From the Tables 1 and 3, it is seen that the responses of two adjacent structures, when they are connected at all the floors with the same damping in all the dampers and when they are connected with $50 \%$ of total dampers with different damping coefficient, are almost nearer. Hence, it leads to conclude that the reduction in the responses, when connected with $50 \%$ of total dampers with different damping in LED is as much as when they are connected at all the floors with the same damping in all the LED, reduces the cost of the dampers almost 50\%.

\section{Conclusions}

The linear elastic seismic behavior of two adjacent structures connected by LEDs is investigated under various earthquake excitations. The governing equations of motion for LED-connected adjacent structures are formulated. The results obtained in this study provide interesting information for the design of LEDs, as summarized below:

1. The LEDs are found to be effective in seismic response reduction of adjacent connected structures.

2. There exists an optimum damping coefficient of LED for minimum earthquake response of the two adjacent coupled structures.

3. The optimum responses are not much affected by a slight variation in the optimum damping coefficient of LED; hence, small variation in damper damping over 
Fig. 13 Control forcedisplacement diagram for 12 th floor LED when the parallel structures connected by LED have different damping under different earthquakes
Fig. 14 Control forcedisplacement diagram for 12 th floor LED when the parallel structures connected at top six floors by LED have different damping under different earthquakes
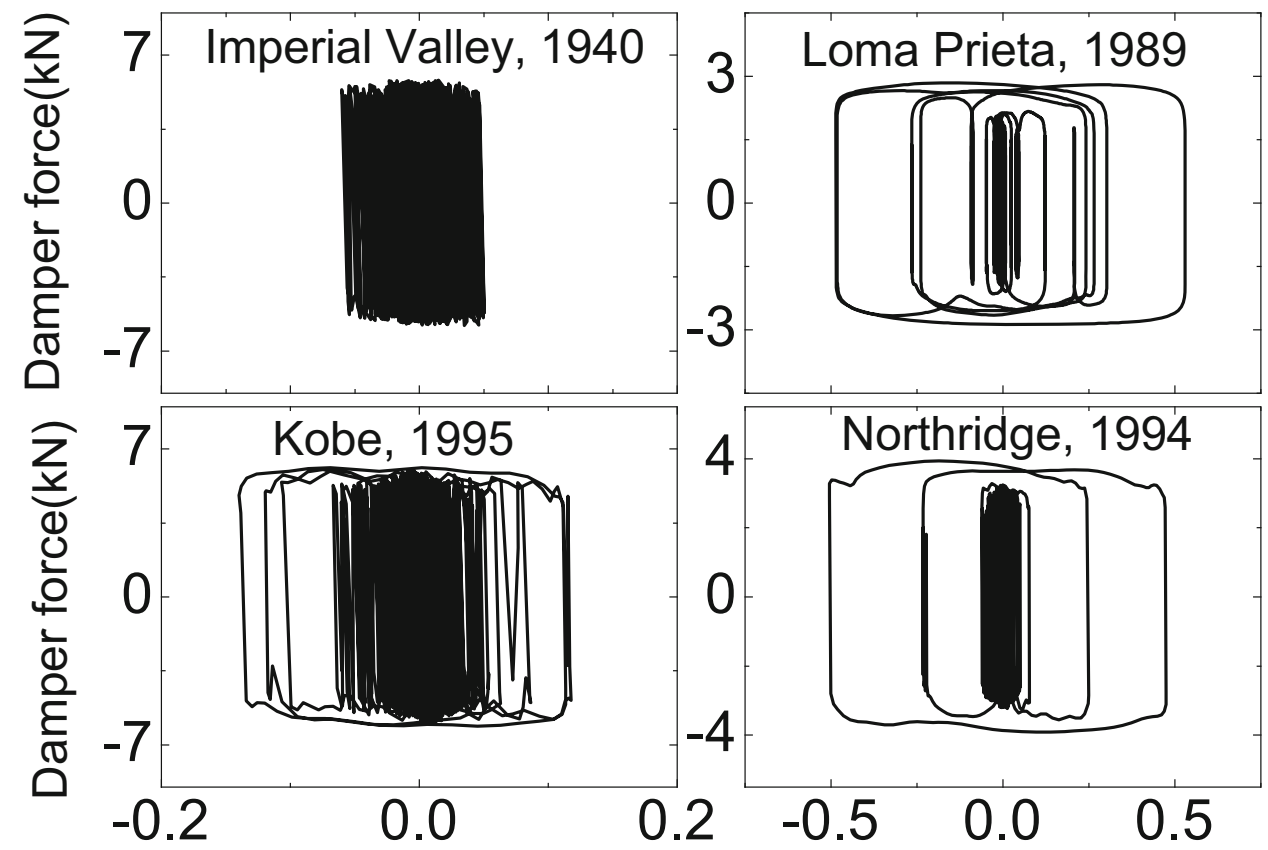

Damper dispalcement(m)

Damper dispalcement(m)

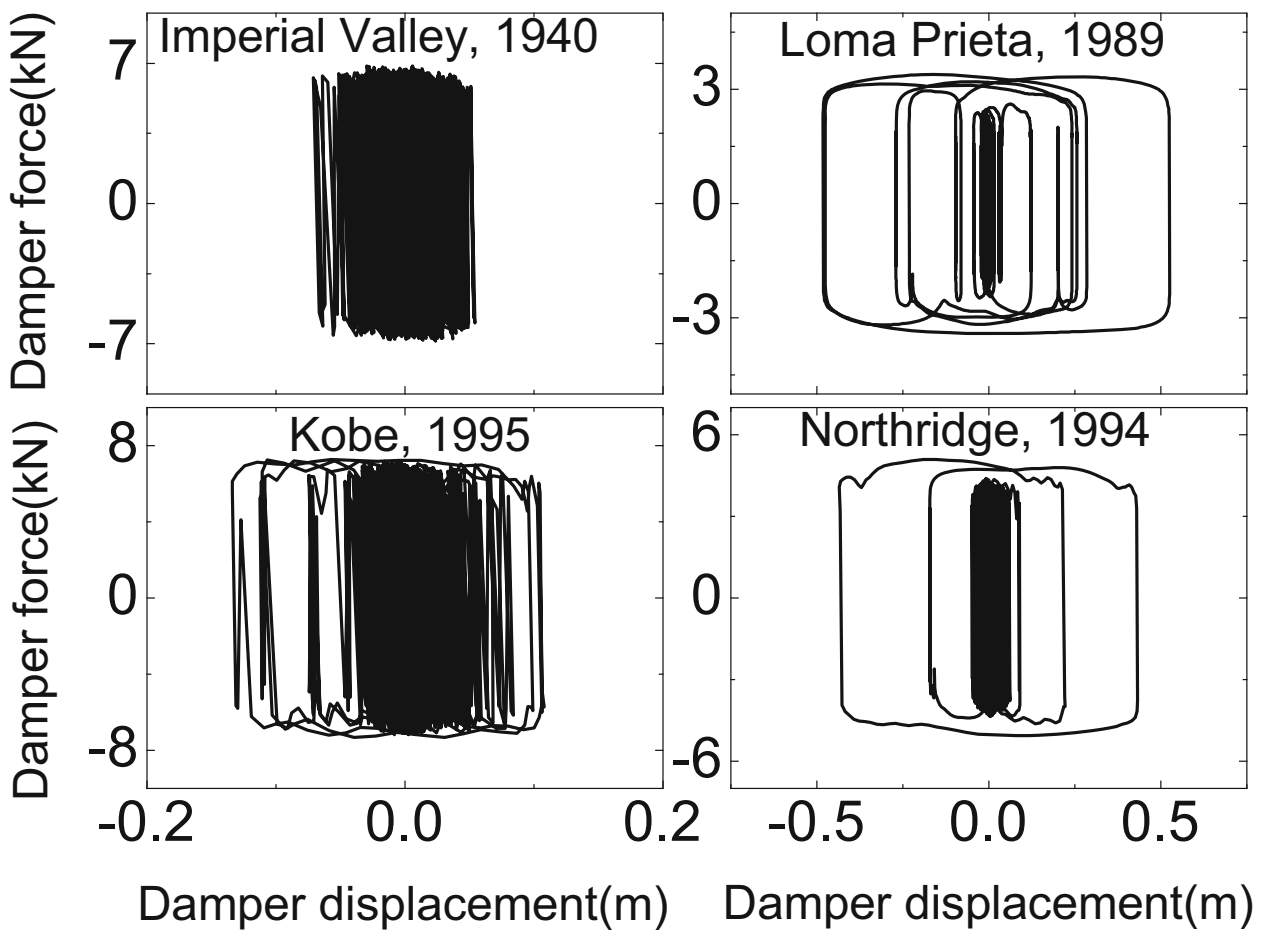

life of the building does not warrant any adjustments or replacement of LED.

4. It is not necessary to connect the adjacent structures by LEDs at all floors; lesser dampers at appropriate locations can significantly reduce the seismic response of the coupled structures.
5. The neighboring floors having maximum relative velocity should be chosen for optimal damper locations.

6. The responses are reduced, when connected with $50 \%$ of total dampers with different damping is as much as when they are connected at all the floors with the same 
damping in all the dampers, results considerable reduction in the damper cost.

The study may be further explored by considering bidirectional ground excitations with torsional effects and for two adjacent structures with similar dynamic characteristics, with different floor heights.

Open Access This article is distributed under the terms of the Creative Commons Attribution 4.0 International License (http://crea tivecommons.org/licenses/by/4.0/), which permits unrestricted use, distribution, and reproduction in any medium, provided you give appropriate credit to the original author(s) and the source, provide a link to the Creative Commons license, and indicate if changes were made.

\section{References}

Betro VV (1987) Observation of structural pounding. In: Proceedings of the International Conference on the Mexico Earthquake, New York, (ASCE), pp 264-278

Bhaskararao AV, Jangid S (2006) Harmonic response of adjacent structures connected with a friction damper. J Sound Vib 292:710-725

Bhaskararao AV, Jangid RS (2007) Optimum viscous damper for connecting adjacent SDOF structures for harmonic and stationary white-noise random excitations. Earthq Eng Struct Dyn 36:563-571

Christenson RE, Spencer BF Jr, Johnson EA, Seto K (2006) Coupled building control considering the effects of building/connector configuration. J Struct Eng ASCE 132(6):853-863

Cousins WJ, Porritt TE (1993) Improvements to lead-extrusion damper technology. Bull $N$ Zeal Natl Soc Earthq Eng 26:342-348

Filiatrault A, Folz B (1992) Nonlinear earthquake response of structurally interconnected buildings. Can J Civ Eng 18(4):560-572
Kasai K, Nakai M, Nakamura Y, Asai H, Suzuki Y, Ishii M (2008a) Current status of building passive control in Japan. In: The 14th World conference on earthquake engineering, Beijing, China

Kasai K, Ooki Y, Ishii M, Ozaki H, Ito H, Motoyui S, Hikino T, Sato E (2008b) Valu-added 5-story steel frame and its components: part-1 full-scale damper tests and analysis. In: The 14th World conference on earthquake engineering, Beijing, China

Matsagar VA, Jangid RS (2003) Seismic response of base-isolated structures during impact with adjacent structures. Eng Struct 25(10):1311-1323

Muthmani K, Gopalkrishnan N, Satish Kumar K, Avinash S, Reddy GR, Parulekar YM (2002) Lead extrusion damping device for passive energy absorption-an experimental study. National Seminar on Seismic Design of Nuclear Power Plants, pp 257-266

Ng CL, Xu YL (2006) Seismic response control of a building complex utilizing passive friction damper: experimental investigation. Earthq Eng Struct Dyn 35:657-677

Pekcan G, Mander JB, Chen SS (1999) Fundamental consideration for the design of non-linear viscous dampers. Earthq Eng Struct Dyn 28:1405-1425

Robinson WH, Greenbank LR (1976) An extrusion energy absorber suitable for the protection of structures during an earthquake. Earthq Eng Struct Dyn 4:251-259

Rodgers GW, Mander JB, Chase JG, Dhakal RP, Leach NC, Denmead CS (2008) Spectral analysis and design approach for high forceto-volume extrusion damper-based structural energy dissipation. Earthq Eng Struct Dyn 37:207-223

Roh H, Cimellaro GP, Lopez-Garcia D (2011) Seismic response of adjacent steel structures connected by passive device. Adv Struct Eng 14(3):499-517

Spence BF Jr, Nagarajaiah S (2003) State of the art of structural control. J Struct Eng 129(7):845-856

Weidlinger $P$ (1996) Passive structural control with sequential coupling. J Struct Eng (ASCE) 122(9):1072-1080

Westermo B (1989) The dynamics of inter-structural connection to prevent pounding. Earthq Eng Struct Dyn 18:687-699 